Recepción: 21/ 12/ 2017

Aceptación: 17 / 02/ 2018

Publicación: 21/ 04/ 2018

Ciencias de la Salud

Artículo de Revisión

\title{
Trabajo de ortodoncia referencias acerca de las extracciones seriadas
}

\author{
Orthodontic work references about serial extractions
}

\section{Referências de trabalho ortodôntico sobre extrações em série}

Julio I. Rosero-Mendoza ${ }^{\text {I }}$

jrosero@outlook.com

Carly L. Núñez-García II carly.nunez@hotmail.com

Fanny A. Mendoza-Rodríguez ${ }^{\mathrm{II}}$ fanny.mendoza@hotmail.com

Correspondencia: jrosero@outlook.com

I Magister en Gerencia Hospitalaria, Especialista en Ortodoncia, Odontólogo, Docente en la Universidad de Guayaquil, Guayaquil, Ecuador.

II Odontóloga, Docente en la Universidad de Guayaquil, Guayaquil, Ecuador.

III Diplomado en Docencia Superior, Magister en Diseño Curricular, Doctora en Odontología, Docente en la Universidad de Guayaquil, Guayaquil, Ecuador. 


\title{
Resumen
}

El tratamiento temprano se recomienda para lograr la mayor cantidad de beneficios para el paciente infantil, incluyendo un mejor aprovechamiento del potencial de crecimiento, menor necesidad de extracción, tratamientos con aparatología fija más acotados con mejores resultados y más estables a largo plazo. A tal efecto se realizó una revisión bibliográfica, con la temática de las extracciones seriadas, definición, técnicas, indicaciones, contraindicaciones. Se concluye, el plan de extracciones seriadas se debe aplicar teniendo en cuenta los requisitos para seleccionar los pacientes, un correcto diagnóstico individual y que se inicie en la época establecida.

Palabras clave: erupción dentaria; extracciones seriadas.

\begin{abstract}
Early treatment is recommended to achieve the greatest number of benefits for the child patient, including a better use of growth potential, less need for extraction, fixed appliances with more fixed treatments with better results and more stable in the long term. To this end, a bibliographic review was carried out, with the theme of serial extractions, definition, techniques, indications, contraindications. It is concluded, the plan of serial extractions should be applied taking into account the requirements to select patients, a correct individual diagnosis and that begins in the established time.
\end{abstract}

Keywords: dental eruption; serial extractions.

\section{Resumo}

O tratamento precoce é recomendado para alcançar o maior número de benefícios para o paciente infantil, incluindo um melhor aproveitamento do potencial de crescimento, menor necessidade de extração, aparelhos fixos com tratamentos mais fixos, com melhores resultados e mais estáveis a longo prazo. Para tanto, foi realizada uma revisão bibliográfica, com o tema extrações seriadas, definição, técnicas, indicações, contraindicações. Conclui-se, o plano de extrações seriadas deve aplicar-se considerando as exigências de selecionar pacientes, um diagnóstico individual correto e que começa no tempo estabelecido.

Palavras chave: erupção dentária; extrações em série. 


\section{Introducción}

La erupción dental es un proceso fisiológico, asociado al crecimiento por el cual el diente se desplaza desde su posición original en el maxilar hasta su posición final en la cavidad bucal. En el ser humano, el proceso de la erupción dental se produce dos veces, primero con la aparición de los dientes temporales o de leche y luego con la erupción de los dientes permanentes ${ }^{1}$.

La formación de los dientes de leche comienza la tercera semana de vida intrauterina. En el nacimiento, el niño ya tiene dentro de los maxilares superiores e inferiores los brotes de los 20 dientes temporales o de leche y las células diferenciadas de los 32 dientes definitivos ${ }^{1}$.

La dentición permanente consta de cuatro incisivos, dos caninos, cuatro premolares y cuatro molares en cada maxilar, además un tercer molar que se encuentra sujeto a anomalías de número, forma y posición. Los dientes permanentes brotan con intervalos de un año entre cada grupo: el primer molar a los 6 años, los incisivos centrales superiores e inferiores a los 7 años, los incisivos laterales superiores e inferiores a los 8 años. El canino inferior y la primera bicúspide superior a los 9 años. El canino superior y la primera bicúspide inferior a los 10 años $^{2}$.

La segunda bicúspide superior e inferior a los 11 años. Los segundos molares superiores e inferiores a los 12 años. Los terceros molares superiores e inferiores de los 18 a los 30 años ${ }^{2}$.

Al igual que para los adultos los niños y jóvenes adolescentes la comunicación y la sonrisa son la puerta de entrada a las relaciones humanas, el cuidado y posición cobra importancia.

\section{Extracción seriada}

Uno de los problemas más controversiales y discutidos en la práctica odontológica, ha sido las extracciones seriadas en el tratamiento ortodóncico en dentición mixta, que consta de una etapa cronológicamente planeadas en intima asociación con el desarrollo del aparato masticatorio, cuyo objetivo es detener o al menos a minorar el curso natural de una maloclusión en lugar de esperar a que los dientes permanentes hagan erupción en posiciones no adecuada; esto implica que este procedimiento constituye una decisión ortodóncico importante, donde el odontólogo necesita conocimientos acerca de la planificación en donde es imprescindible conocer los elementos necesarios para saber en casos se indican ${ }^{3}$. 
La extracción seriada es un procedimiento dentro del campo de la ortodoncia interceptiva, que se puede aplicar en casos de discrepancia oseodentaria, donde el hueso de soporte es menor a la suma del tamaño del material dentario ${ }^{4}$.

La extracción seriada precede a un estudio minucioso de la situación dental de un niño desde los 6 años de edad, momento de la erupción del primer molar permanente. Es importante un buen registro radiográfico de la dentición posterior a la erupción de los primeros molares, desde ese momento nos encontramos en el periodo que conocemos como dentición mixta. Consiste en la extracción de determinadas piezas dentarias temporales y permanentes siguiendo un orden predeterminado durante la dentición mixta en casos de una discrepancia óseo 'dentaria en la que vemos que podemos conseguir una oclusión normal o bien con las extracciones, disminuir la complejidad del tratamiento ortodóncico a realizar. Según otros autores definimos la extracción seriada como el programa de extracciones encaminado a interceptar una maloclusión ${ }^{5}$.

A manera de resumen final, la extracción seriada puede definirse como la remoción de ciertos dientes deciduos y permanentes que, de forma correctamente planificada y secuenciada en el tiempo durante el periodo de dentición mixta, consiguen:

- Reducir el apiñamiento incisivo en los casos de discrepancia óseo-dentaria.

- Permitir una guía de erupción a los dientes aún no erupcionados con el fin de mejorar su posición futura (sobre todo los caninos).

- Disminuir o eliminar el periodo de terapia con aparatología fija.

Cuando realizar las extracciones seriadas y cuando no es de vital importancia: El arco mandibular es la guía diagnóstica final, particularmente la correcta relación de los incisivos con respecto al hueso alveolar basal.

Es importante conocer que los incisivos mandibulares sólo son estables cuando tienen una posición adecuada, con respecto a su base ósea. De igual importancia es saber que los caninos temporales deben de permanecer en boca hasta la edad normal para su exfoliación, ya que estos mantienen la longitud de la arcada durante el recambio de los incisivos (siempre y cuando las estructuras de soporte sean adecuadas). 


\section{Técnica de extracción seriada}

Después del examen clínico y el estudio de todos los exámenes complementarios el profesional decidirá si se debe o no hacer las extracciones.

Si la respuesta es afirmativa deberá decidir si debe extraer los primeros molares deciduos o los caninos y cuando deberá hacerlo.

Existen tres fases dentro de esta técnica:

Primera fase: los caninos temporales inferiores, son extraídos después de la erupción de los incisivos laterales inferiores permanentes.

Los caninos temporales superiores son extraídos, de ser posible antes de la erupción de los incisivos laterales superiores permanentes. Se nota un mejoramiento en el alineamiento de los incisivos ya sea que estén linguales o labiales, ellos se alinean en el espacio creado por la extracción de los caninos temporales.

Segunda fase: remoción de los primeros molares caducos, para acelerar la erupción de los primeros premolares para que esta erupción en antes de los caninos y haya una inversión en la secuencia normal de erupción.

Los primeros molares deciduos deben ser extraídos después de que los primeros premolares, hayan sobrepasado el estadio 6 de Nolla, con el fin de que la erupción sea acelerada, si son extraídos antes, habrá un retraso en la erupción de los premolares.

Tercera fase: durante esta fase del tratamiento se extraen los cuatro primeros premolares antes de la erupción de los caninos permanentes, con el fin de asegurar el ajuste de los caninos permanentes dentro del espacio creado, el mejor ajuste se logra si los caninos permanentes pueden erupcionar dentro del espacio creado que moverse hacia ese espacio.

El tiempo más favorable para la extracción de los primeros premolares, depende de la secuencia de erupción de caninos y primeros premolares, depende del examen radiográfico. Existen tres posibilidades: 
Si las radiografías muestran que los primeros premolares erupcionaran antes que los caninos, la extracción del premolar es detenida hasta que el primer molar temporal sea exfoliado naturalmente y el primer premolar haga su erupción, se ve con frecuencia en el arco maxilar.

Si las radiografías muestran que el canino y el premolar van erupcionando al mismo tiempo y nivel, el primer molar temporal es extraído para permitir la erupción del primer premolar antes que del canino.

Si las radiografías muestran que el canino erupcionara antes que el premolar, los primeros molares temporales y primeros premolares aun sin erupcionar deberán ser extraídos quirúrgicamente ${ }^{6}$.

\section{Indicaciones}

En mal oclusiones clase I dentales y esqueléticas que muestre una verdadera desarmonía entre el tamaño del diente y el hueso basal.

Deberá haber una discrepancia de por lo menos 10-12 mm de exceso de tejido dental mediante un análisis de dentición mixta.

Deberá haber un buen perfil facial y una sobre mordida vertical normal.

El paciente deberá estar entre los 7 a 10 años de edad dental ${ }^{6}$.

La mejor época para iniciar la extracción seriada, es cuando han hecho erupción los cuatro incisivos inferiores y cuando están erupcionando los incisivos laterales; esto es, cuando el niño ha cumplido los 8 o 9 años de edad, previo a un análisis radiográfico y del espacio.

\section{Contraindicaciones}

Mal oclusiones clase I, donde el apiñamiento es muy ligero o

Mal oclusiones clase II división II

Mal oclusiones clase III

Cuando los primeros molares permanentes se encuentran en mal estado con la posibilidad de perderse tempranamente.

Ausencia congénita de segundos premolares. 
Mal oclusiones clase I con pérdida de espacio en el arco mandibular y con espacio adecuado en el arco maxilar.

En sobre mordidas verticales profundas, donde los incisivos mandibulares ocluyan contra la encía palatina, lingualmente a los incisivos centrales superiores.

Cuando existan diastemas entre los incisivos centrales superiores, primero se aconseja cerrarlo, antes de extraer los caninos temporales superiores ${ }^{6}$.

\section{Ventajas y desventajas de la técnica de extracción seriada}

La técnica de extracción seriada como todo método tiene muchos puntos a favor y en contra.

Entre las ventajas podríamos decir que se mejora el apiñamiento en el sector de los incisivos, mejora las condiciones de higiene minimizando el riesgo de caries dental y enfermedad periodontal debido al alineamiento dental, ya no se necesitara usar aparatología per si el caso lo amerita será menos complicada, mucho más sencilla y a corto plazo representando menos gasto para el paciente.

Después de la erupción de todos los dientes, a veces es necesario el uso de aparatología fija para corregir pequeñas imperfecciones dejadas por las extracciones seriadas.

Las desventajas presentes en esta técnica tenemos la falta de cooperación por parte del paciente en el momento de realizar las extracciones, reducción de la curva de Spee, en muy pocos casos se presenta la lingualizacion de los incisivos con presencia de resalte y sobre mordida vertical.

En adición los segundos premolares irrumpen con inclinación axial hacia mesial. Si no se da tratamiento surgirán problemas de tipo periodontal.

Las extracciones seriadas cuando son bien conducidas, pueden presentar resultados satisfactorios y de esta manera ayudar a resolver problemas ortodóntica cada vez más crecientes en la población $^{7,6}$.

Morgado Serafín ${ }^{8}$, en su investigación obtuvo como resultado que la mayoría de los pacientes presentaron extracciones prematuras de ambos caninos temporales, predominio del perfil convexo y recto, colapso del sector antero inferior y aumento del sobrepase coincidiendo con datos obtenidos por otros autores extranjeros. 
Para concluir, el plan de extracciones seriadas se debe aplicar teniendo en cuenta los requisitos para seleccionar los pacientes, un correcto diagnóstico individual y que se inicie en la época establecida.

\section{Referencias Bibliográficas}

1- Díaz Martínez C. Erupción dentaria. 2016 [citado 28 enero 2018. Disponible en:]http://hospitaldenens.com/es/guia-de-salud-y-enfermedades/erupcion-dentaria/

2- Mayoral J, Mayoral G. Ortodoncia, principios fundamentales y prácticos. $4^{\mathrm{a}}$ ed. Ciudad de La Habana: Editorial Científico-Técnica; 1986

3- Guzmán Martínez, Linda Margarita; Juárez Membreño, Israel Antonio y Montano Guzmán, Miriam Guadalupe. Indicaciones para realizar extracciones seriadas en el tratamiento ortodóntico en dentición mixta. Investigación documental. 2004 [citado 28 enero 2018]. Disponible en : http://ri.ues.edu.sv/8008/

4 Guardia López I. La extracción seriada: Manejo ortodóncico y aplicación clínica. Ortod. Esp. 2010; 50 (5); 508-516

5- Martinez Carmen. Extracciones seriadas. 2015. [citado 28 enero 2018]. Disponible en: https://es.scribd.com/document/269830043/Extracciones-Seriadas

6- Guamán Narváez L. Técnica de extracción seriada en el tratamiento del apiñamiento dentario. 2012. Universidad de Guayaquil. [citado 28 enero 2018]. Disponible en :repositorio.ug.edu.ec/bitstream/redug/2757/1/Lorena\%20Guaman.pdf

7- Graber Thomas, ortodoncia, principios y técnicas actuales 4ta edición, España, 2006 Editorial Elsevier Mosby, Páginas 439 - 442

8- Morgado Serafín D. Extracciones prematuras de caninos temporales como causa de iatrogenia. 2000. [citado 28 enero 2018]. Disponible en :http://bvs.sld.cu/revistas/mciego/vol10_sulp1_04/articulos/a11_v10_supl104.htm 